www.periodicos.unimontes.br/index.php/caminhosdahistoria

\title{
DA INTRODUÇÃO AO APEGO: OS PRIMEIROS LANCES DO FUTEBOL NO ESTADO DO RIO DE JANEIRO (1910-1930)
}

\author{
Agnaldo Kupper ${ }^{1}$
}

Resumo: Necessário entender como se processou e processa a apropriação do futebol entre os que dele fizeram e fazem um meio para atender a objetivos pessoais, familiares e de grupos. Não se pode negar que, particularmente no Brasil, a prática futebolística está inserida nas relações sociais e, como tal, sujeita a novas participações, a novos sentidos e significados. Desta forma, é parte integrante das mudanças engendradas pelo processo histórico do país. Caso do Estado do Rio de Janeiro que, nas primeiras décadas do século XX assistiu a uma assustadora proliferação de clubes de futebol, a princípio restrito a indivíduos privilegiados socialmente. Os benefícios dados para a estruturação e manutenção de diversas agremiações deixaram legados sentidos nos dias contemporâneos. A documentação obtida nos arquivos dos clubes - tal como cartas, relatórios, atas, circulares e estatutos - atesta investimentos de empresas em práticas esportivas como o futebol. Criados por trabalhadores, muitos desses clubes buscaram apoio para suas atividades junto às direções patronais, apoio este material e financeiro, como cessão de terreno para estruturação de campo e sede, material de jogo, aluguéis, uniformes, deslocamentos dos praticantes, bolas, entre outros. Não sem intenções. Daí a importância da análise de documentos empresariais.

Palavras-chave: Futebol; Brasil; patrocínios; benefícios; dividendos.

Abstract: It is necessary to understand how the appropriation of football was processed and processed among those who made it and make a means to meet personal, family and group goals. It cannot be denied that, particularly in Brazil, football practice is inserted in social relations and, as such, subject to new participations, new senses and meanings. Thus, it is an integral part of the changes engendered by the country's historical process. Case of the State of Rio de Janeiro that, in the first decades of the 20th century, witnessed a frightening proliferation of football clubs, at first restricted to socially privileged individuals. The benefits given for the structuring and maintenance of several associations have left legacies felt in contemporary days. The documentation obtained from the club's archives - such as letters, reports, minutes, circulars and statutes - attests investments by companies in sports practices such as football. Created by workers, many of these clubs sought support for their activities from employers 'boards, this material and financial support, such as the transfer of land for structuring the field and headquarters, game material, rent, uniforms, practitioners' displacements, balls, among others. Not without intentions. Hence the importance of analyzing business documents.

Keywords: Football; Brazil; sponsorships; benefits and dividends.

1 Professor e Doutor na área de História e Sociedade (Unesp). Escritor. Email: agnaldokupper2009@ hotmail.com. ORCID: https://orcid.org/0000-0001-7547-2334. 


\section{Introdução}

O futebol brasileiro atravessou diversas fases dentro de seu desenvolvimento: de 1894 a 1904, restrito a centros urbanos; de 1905 a 1932, popularizou-se, principalmente através de subsídios cedidos por indivíduos e grupos; a partir de 1933, profissionalizou-se; durante a década de 1950, consolidou-se como esporte de massa, ganhando contornos de espetáculo cerca de duas décadas após. Ou seja, o futebol, inicialmente foi praticado por privilegiados sociais, tomou conta do país enquanto prática popular, passando a ser utilizado de forma gradativa como instrumento político, ao menos até a sua espetacularização contemporânea, o que significa dizer que o futebol se desenvolveu em solo brasileiro de acordo com as transformações sociais, econômicas, políticas e culturais do país.

A penetração de práticas esportivas como o futebol entre as camadas sociais menos privilegiadas significa a consolidação de novos hábitos culturais, a que Pierre Bourdieu denomina 'violência simbólica', apontando à adesão de um conjunto de hábitos e práticas representativas que definem certo estilo de vida:

A violência simbólica consiste em uma violência que se exerce com a cumplicidade tácita dos que a sofrem e também, com frequência, dos que a exercem, na medida em que uns e outros são inconscientes de exercê-la ou de sofrê-la (BOURDIEU, 1997, p. 22).

Pierre Bourdieu entende o esporte moderno como um fenômeno em que se atribui posições relacionadas ao capital social, econômico e cultural de cada agente. A busca pela hegemonia de determinadas práticas seria o acúmulo de uma distinção social de acordo com o seu potencial de poder simbólico.

Para se compreender o esporte, segundo Bourdieu (1997), seria necessário conhecer e reconhecer a posição que determinada atividade esportiva ocupa por meio da distribuição dos praticantes segundo a colocação do mesmo no espaço social, apontando para a necessidade de se perceber o tratamento do esporte na condição de fenômeno inscrito em um sistema mercadológico.

Marivoet (2013) reforça os entendimentos de Bourdieu ao estabelecer que práticas e gostos culturais constituem elementos indicadores da condição do indivíduo em uma estrutura social, incluindo aí os hábitos esportivos e as práticas de lazer.

No Brasil, a existência de numerosos portos, aliada ao grande território do país, torna difícil precisar um local correto da introdução do futebol. No entanto, São Paulo - até pelos inúmeros empreendimentos e investimentos ingleses - teria sido a primeira cidade brasileira a 
assistir a pelejas disseminadas pelas suas vias, porém acompanhada bem de perto pelas partidas de futebol improvisadas da cidade do Rio de Janeiro.

As cidades de São Paulo e Rio de Janeiro assumiram o papel de destaque no futebol desde o início do século XX, independentemente do pioneirismo da prática. A primeira pelo desempenho econômico; a segunda por ser o centro político do país. Desta forma, deve ser visto como natural o fato de terem sido criadas nestas duas cidades as duas primeiras entidades gerenciadoras da modalidade esportiva no Brasil: a Federação Brasileira de Futebol, em 25 de setembro de 1915, em São Paulo, e a Federação Brasileira de Esportes, em 15 de novembro de 1915, no Rio de Janeiro. Mas o destaque que é dado a São Paulo e Rio de Janeiro enquanto centros propulsores do futebol é confirmado por existirem nestes centros registros históricos mais abundantes.

Nas primeiras décadas do século XX, no contexto da fase de popularização do futebol, o movimento operário brasileiro postou-se de forma ruidosa. Apesar da ação repressiva governamental, a nascente burguesia industrial brasileira, inquieta diante das mobilizações sindicais proletárias, teria feito uso de mecanismos menos duros como apoiar e financiar o esporte que caíra nas graças operárias. A estruturação de diversas agremiações de futebol, a partir da popularização desse esporte, atendeu a diversas outras intenções, além do controle sobre o tempo livre dos trabalhadores: lazer, promoção pessoal e familiar, interesses comerciais e políticos de indivíduos e grupos.

O futebol e seu desenvolvimento e expansão teriam feito parte de uma estratégia dos empregadores e patrões, em geral para recuperar o controle e harmonizar a produção. A atividade seria uma poderosa aliada da disciplina operária (HERSCHMANN; LERNER, 1992).

Para comprovar a ligação do futebol com empresas e trabalhadores, necessária a consulta a acervos diversos, caso da Federação Paulista e Fluminense de Futebol. Vale lembrar que apenas há cerca de duas décadas os clubes paulistas e fluminenses - assim como as Federações locais do Rio de Janeiro e São Pauoo - passaram a valorizar a preservação de suas respectivas histórias. Muitos documentos, no entanto, perderam-se por falta de conservação ou são, em exagero, superficiais. Atas de diretorias e de Assembleias Gerais de clubes também se apresentam mal conservados e desorganizados, assim como súmulas de jogos e diversas imagens (em especial as do primeiro quartel do século passado). A documentação obtida nos arquivos dos clubes, tal como cartas, relatórios, atas, circulares e 
estatutos $^{2}$, atestam investimentos de empresas em práticas esportivas como o futebol. Afinal, vale lembrar que o número de clubes de futebol nas primeiras décadas do século XX não parou de crescer. Também a identificação da trajetória de muitas personalidades envolvidas com o futebol exige o cruzamento de dados, tal qual uma investigação jornalística. Desta forma, análises biográficas, declarações pessoais informais, trajetórias políticas individuais, informações empresariais, promoções de encontros através de convites, pesquisas de origem e filiação de famílias, anúncios jornalísticos e levantamentos genealógicos, entre outros, tornaram-se fundamentais para o que se deseja comprovar: o futebol no Brasil teve sua promoção, em grande parte, aos interesses dos desejosos em jogá-los e os interesses dos que favoreceram o jogo. Normalmente, não sem intenções.

\section{O futebol apropriado por privilegiados do Rio de Janeiro}

Proveniente da Suiça, após anos de estudos, Oscar Cox, em 1897, teria sido o introdutor do futebol na capital federal, Rio de Janeiro. Porém, persistem dúvidas a respeito, uma vez que registros pouco confiáveis atestam que marinheiros estrangeiros já o praticavam no cais do porto. Alguns testemunhos, também pouco confiáveis, dão conta que, paralelamente aos marinheiros, nos colégios mais refinados da cidade o football já seria uma prática comum (ETCHEGARAY, 1932, p.17).

Mesmo que não tenha sido Oscar Cox o introdutor do futebol na capital federal, foi seu grande incentivador e referência.

Em 22 de fevereiro de 1901, apontamentos indicam que a realização da primeira partida oficial de futebol na cidade do Rio de Janeiro aconteceu no Rio Cricket and Atletic Association, entidade fundada em 1896 por ingleses em Niterói ${ }^{3}$. Por tais indicativos, o número de jogadores era maior que o público presente; a partida foi considerada oficial por dispor de equipes uniformizadas, ter sido realizada em campo regulamentar e ser jogada com bola padronizada da época. Resultado da peleja: empate em um gol, ressaltando que a partida teve dois tempos de vinte minutos.

O futebol ainda não havia caído nas graças dos cariocas e fluminenses, ao contrário da Europa, onde a prática já fora absorvida pelo gosto popular, principalmente entre operários,

\footnotetext{
${ }^{2}$ Resumidamente, balancetes são demonstrativos contábeis que reúnem contas de movimento de uma empresa; atas são documentos que registram de forma resumida as deliberações, ocorrências e decisões de reuniões e assembleias; estatutos são documentos que agrupam as normas jurídicas que regulam as relações entre os indivíduos que têm algo em comum (regulamento do funcionamento de uma pessoa jurídica): circulares entendidas como comunicações enviadas a determinado grupo associado sobre assuntos de interesse geral.

3 Jornal do Comércio, 1906 , edição 00049.
} 
caso das cidades inglesas de Manchester e Nottingham.

Na busca do incentivo à prática do futebol no Rio de Janeiro, foi marcada uma nova partida, com boa cobertura da imprensa carioca, principalmente dos jornais $O$ Correio da Manhã e Jornal do Brasil: de um lado uma equipe do Rio de Janeiro; de outro, uma paulista. Final da peleja: empate. Por mais que alguns veículos impressos tenham destacado o encontro do dia 19 de outubro de 1901, pouco entusiasmo na capital federal com o evento.

No ano seguinte, especificamente em 21 de julho de 1902, foi fundado o Fluminense Football Club. Seus sócios eram basicamente estudantes provenientes do velho continente e a agremiação foi a primeira a ter como objetivo essencial a prática do futebol (A GAZETA DE NOTÍCIAS, 1906; COELHO NETO, 1969).

Em 1903, surgiu o Foot-ball and Atletic Club, fundado em 27 de Setembro. Aos poucos, outras agremiações foram inserindo a prática na cidade, caso do Club de Regatas do Flamengo e do América Football Clube. Porém, as joias e as mensalidades ${ }^{4}$ para ingresso e manutenção nessas agremiações eram altíssimas, impossibilitando acesso popular.

No caso do Bangu Atletic Club, fundado em 17 de abril de 1904, a Companhia Progresso Industrial (criada como fábrica de tecidos no bairro do mesmo nome e com capital português, em 1892), apropriou-se do futebol a partir de técnicos ingleses que passaram a praticá-lo, a princípio sem o apoio da direção da empresa. O Bangu distingue-se de outros clubes do Rio de Janeiro por ser o precursor da democratização do acesso ás práticas futebolísticas, por ter sido o primeiro time operário do Rio de Janeiro, por ter dado aos jogadores-operários privilégios (abono de faltas e garantia de emprego, por exemplo), por receber por parte da diretoria certo paternalismo da Companhia Progresso e por iniciar a subordinação à vigilância das ações operárias, demonstrando dependência e o interesse dos trabalhadores em fazer parte de uma "elite operária". O campo do Bangu transformou-se em um "quintal" da fábrica, numa espécie de continuidade do espaço de trabalho (PEREIRA, 2000, p. 259).

No mesmo ano de 1904 surgiu o Botafogo Foot-ball Club, especificamente em 19 de setembro. No time do bairro de mesmo nome, a ideia foi formar uma agremiação autêntica de brasileiros praticantes de futebol. A mensalidade estipulada foi de $2 \$ 000$. No ano seguinte, tal a procura por interessados em associar-se ao clube, a contribuição foi majorada para $5 \$ 000^{5}$, restrita, portanto, a jovens abastados ou provenientes de famílias socialmente privilegiadas.

\footnotetext{
${ }^{4}$ Joia: taxa mais elevada para que um novo integrante seja aceito na agremiação; mensalidade: taxa mensal paga pelo associado para frequentar as dependências da agremiação, sob o pretexto de manutenção das estruturas da mesma

${ }^{5}$ Atas do Botafogo FC, 1904 e 1905.
} 
O América Foot-ball Club, por sua vez, originou-se de uma dissidência do Club Atlético da Tijuca, tendo como associados iniciais membros das camadas sociais mais privilegiadas da cidade do Rio de Janeiro, com destaque à família Morsted, fundadora e organizadora da agremiação ${ }^{6}$.

Daí para frente, mais clubes foram surgindo: Riachuelo, Cosme Velho FC, Boêmios FC, Humaitá FC e Brazilian FC (PEREIRA, 2000).

$\mathrm{O}$ incremento no número de clubes de futebol na cidade do Rio de Janeiro nos primeiros anos do século XX demonstra o interesse pelo esporte (em especial pela juventude carioca mais abastada). O grande atrativo para os membros era pertencer a agremiações seletivas, sendo, portanto, indicativo de certa diferenciação social. A formação dessas agremiações - excetuando o Bangu A.C. - são exemplos de mecanismos sociais segregadores, ou seja, os clubes estruturados nas zonas centrais e sul da cidade se organizavam em torno da elite social privilegiada da cidade-capital republicana:

$\mathrm{Na}$ verdade, a sociedade e a cultura da elite na capital continuaram a promover e a defender os interesses desta elite, ajudando a criar um sentimento de continuidade aristocrática, estabelecendo locais exclusivos para contatos e alianças, reforçando valores e pressupostos compartilhados se, mais importante talvez, promovendo um sentimento de legitimação (NEEDELL, 1993, p. 31).

No Rio de Janeiro, o futebol ganhou maior projeção após a reurbanização da cidade durante o governo presidencial de Rodrigues Alves (1902-1906), sob coordenação do então prefeito Francisco Pereira Passos. Houve uma clara visão positivista nas reformas urbanísticas implantadas.

$\mathrm{Na}$ modernização da capital federal (também com interesse de consolidar o regime republicano no país e incorporar a cidade ao "mundo civilizado", afinal era o principal núcleo urbano do país), centenas de habitações de segmentos sociais menos favorecidos foram colocadas abaixo para dar lugar, entre outros, a suntuosas avenidas. A grande parcela da população prejudicada pelas obras não tardou a revoltar-se, fazendo surgir a primeira grande revolta urbana da história brasileira: a Revolta da Vacina ${ }^{7}$ (1904), reprimida com a força da polícia e, quem sabe, com o estímulo ao futebol nos terrenos baldios e nas praias, em especial

\footnotetext{
${ }^{6}$ Estatutos do América Football Club; Roberto Assaf \& Clóvis Martins. História dos Campeonatos Cariocas de Futebol: 1906-2010. Rio de Janeiro: Maquinária Editora, 2019, p. 10-19.

7 A Revolta da Vacina teve como motivação não apenas a obrigatoriedade da vacinação contra a varíola. Foi gerada também pela insatisfação popular ante as transformações urbanas da capital, o aumento do custo de vida, a intransigência governamental e a ausência de participação popular nas decisões políticas na República recém instalada.
} 
entre as maltas(grupo de capoeiristas), já que a prática da capoeira passou a ser incessantemente perseguida após o apoio destes às manifestações ocorridas na cidade (AQUINO, 2002, p. 45).

O futebol, neste início do século XX, estava intimamente ligado ao processo de modernização pelo qual passava a cidade do Rio de Janeiro e dessa maneira era uma tipificação dos valores daquela sociedade (MALAIA, 2008)’ Segundo Shirts (1982), não apenas o futebol, mas também

(...) O chá da tarde, a moda, o mobiliário das casas, o envio de rosas às senhoras. (...) Havia, pois uma extrema valorização dos hábitos estrangeiros pelas elites urbanas brasileiras em ascensão. (...) Ocorreu uma nivelação de gostos e atitudes: modo capitalista de pensar, agir e ter gosto esportivo. (SHIRTS, 1982, p. 91-92).

Ou seja, na transição do século XIX para o século seguinte, a cidade do Rio de Janeiro viveu uma série de transformações, acompanhada de um impulso esportivo. Para os mais abastados, a intenção do culto ao corpo através de práticas como o futebol, o remo, o turfe e o ciclismo. Afinal, com a intenção de inserir a capital federal no mundo civilizado, caberia às elites sociais e a membros médios urbanos a procura de distinção social; associar-se a uma agremiação esportiva seria o "carimbo" demonstrador da inserção do indivíduo nos novos tempos.

Para os menos favorecidos, o lazer à sua maneira. $\mathrm{O}$ futebol, até pela não exigência de equipamentos sofisticados, estruturava-se como possibilidade de abandono à condição de meros espectadores para a condição de protagonistas. Isto significa que, se para os habitantes de maior renda da capital federal as disputas futebolísticas (partidas) eram usadas como forma de diferenciação social; para os de menor poder aquisitivo, entretenimento.

Progressivamente foram surgindo mais clubes nesta primeira década do século XX, muitos deles como pontos de diversão, tais como o Aldeia Campista FC e o Boêmios de Vila Isabel $\mathrm{FC}^{8}$. Desta forma, o futebol tendia a organizar-se em clubes de regiões suburbanas da cidade do Rio de Janeiro, caso do Pedregulhense Futebol Club, do Sport Club Mangueira, do São Cristóvão FC, do Club Athetico Meyer, do Nacional Football Club, do Guarany Football Club, do Alumínio Football Club, do Shoot Americano Football Club, do Mauá Football Club, do Eden Brasil Football Club, entre diversos outros. Organizar uma agremiação (fosse ela de dança, carnaval, leitura, xadrez ou futebol) mostrava-se como uma tentativa de acompanhar o que ocorria nas zonas mais privilegiadas e valorizadas da cidade, concedendo

\footnotetext{
${ }^{8}$ O Paiz, 06 de setembro de 1905.
} 
aos dirigentes certa notoriedade, mesmo que local (apropriação de capital simbólico).

Fato que as agremiações de futebol expandiram-se consideravelmente nas duas primeiras décadas no Rio de Janeiro. Boa parte delas, seletiva (cobrando joia e mensalidades significativas), restringindo a participação popular (com exceção de clubes formados em regiões suburbanas da capital federal).

Em 08 de julho de 1905, na sede do Fluminense, representantes do Botafogo, do Atletic and Foot-ball Club, do próprio Fluminense e do Bangu (este representado por um diretor da fábrica), resolveram fundar uma liga para organizar a prática do futebol (estruturação de torneios e disputas entre clubes que dessem visibilidade à prática, atraindo público e renda, além de proteção às agremiações componentes desse tipo de associação) na cidade através de campeonatos: a Liga Metropolitana de Foot-ball ${ }^{9}$. Uma das intenções da entidade era evitar a infiltração de clubes populares na capital federal, criando mecanismos protetores que mantivessem o futebol sob o controle de um restrito segmento social. Para tanto, para constituir-se, um clube passaria a ter que pagar à liga 50\$000 anuais e 30\$000 de mensalidade, além da aceitação pelo mesmo de incorporação à entidade recém surgida, impedindo o acesso em seus quadros de trabalhadores manuais ${ }^{10}$.

Mais popular, uma semana após as determinações da Liga Metropolitana, o Bangu AC, ao não aceitar tais imposições, desligou-se da entidade (PEREIRA, 2000). Isto porque, pela forma como surgiu e desenvolveu-se, o Bangu proletarizou-se e já havia determinado em seus estatutos a presença de sócios das mais diversas origens em seus quadros, além de permitir o comparecimento dos operários da fábrica nas pelejas que o clube disputava.

O desligamento do Bangu da Liga não teria incomodado as demais agremiações, até pela distância que devia ser percorrida pelos clubes filiados à entidade para as partidas naquele bairro operário. Além disso, na procura por manter em suas estruturas clubes elitizados, causava certo mal-estar à Liga ver surgir agremiações menores e proletárias a partir do exemplo dado pelo Bangu, caso do Sport Club Mangueira e do Esperança (também formado por funcionários da Companhia Progresso Industrial do Brasil). Para tê-los sob domínio, a Liga procurou incorporar tais agremiações, porém relegando-as à segunda divisão sob o argumento de prestigiar os clubes mais antigos e precursores da organização.

Durante o ano de 1906 teriam sido fundadas mais de trinta agremiações de futebol na capital federal, todas elas ligados às famílias mais ricas da cidade, em clubes restritos, devendo ser ressaltado, no entanto, que populares, mesmo sem acesso a tais organizações,

\footnotetext{
9 "Sport". O Malho, 07 de outubro de 1905.

10 "Gazeta dos Sports". Gazeta de Notícias, 10 de maio de 1907.
} 
procuravam uma brecha que lhes permitisse assistir aos jogos disputados em festivais, tal a curiosidade pelo esporte. Em 1907, o número de clubes na cidade chegou a quarenta, segundo dados esparsos obtidos junto à Federação de Futebol do Estado do Rio de Janeiro. Na ocasião, a capital federal contava com 662 estabelecimentos industriais e 34.850 operários, passando a apresentar aspectos de metrópole (CARONE, 1979, P. 77).

Como a adesão à Liga Metropolitana mostrava-se muito restritiva, foram sendo desenhadas novas organizações, novas ligas (como a Liga Suburbana de Football, criada em 1907) e novos campeonatos para que fossem abrigadas as novas associações de futebol. Ao surgir, a Liga Suburbana de Football teve a intenção de agregar equipes modestas que não apresentassem condições materiais e de estrutura para participação nos torneios da Liga Metropolitana.

Outras ligas alternativas suburbanas foram sendo estruturadas no Rio de Janeiro como forma de dar estrutura organizacional a torneios que promovessem embates entre agremiações. A multiplicação de clubes na cidade-capital foi tão intensa que, em 1914, a Liga Metropolitana propôs uma terceira divisão em seus quadros. A medida deixou clara a intenção de separar clubes de classes sociais distintas, afinal as regras da Liga apontavam que o vencedor da segunda divisão subiria à primeira e o último da primeira teria que acatar o descenso à segunda divisão. Desta forma, abria-se um precedente perigoso ao elitismo carioca. Ao perceber a ameaça, no ano seguinte surgiu uma proposta de se fazer uma série operária dos clubes, preservando o elitismo de várias as agremiações. Desta forma, os clubes filiados à entidade seriam divididos em três séries: uma para trabalhadores não-braçais, outra para operários e outras profissões braçais e uma terceira para praças e soldados.

No ano de 1915, estruturou-se o Clube de Regatas Vasco da Gama, agremiação composta, a princípio, por membros da colônia portuguesa da cidade do Rio de Janeiro, em sua maioria prósperos comerciantes locais (ROCHA, 1975).

As estatísticas relativas à prática do futebol na cidade do Rio de Janeiro indicam que as três principais ligas da capital federal (Liga Metropolitana, Liga Suburbana e Associação Atlética Suburbana) apresentaram o registro, no ano de 1919, de mil cento e noventa e dois jogadores participantes entre cinquenta e seis clubes (PEREIRA, 2000, p.38). O jornal $O$ Imparcial, no entanto, calculou entre "quatro e cinco mil o número de praticantes de futebol, argumentando que deveriam ser considerados clubes não filiados às Ligas constituídas ou filiados a ligas menores e independentes" $" 11$.

\footnotetext{
${ }^{11}$ O Imparcial, 28 de abril de 1919.
} 
A título de projeção, considerando que dos 1.157 .873 habitantes do Rio de Janeiro, cerca de seiscentos mil eram homens (segundo recenseamento brasileiro divulgado em setembro de 1920), dois em cada cem moradores do sexo masculino da cidade praticavam futebol em 1919.

No primeiro quartel do século XX, na formação de novos clubes de futebol no Rio de Janeiro manteve-se a associação por vizinhança, caso do Cascadura FC, Bonsucesso, Santa Thereza FC, Engenho de Dentro Athletic Club (fundado em 03 de novembro de 1912 e que teve grande destaque no futebol suburbano do Rio de Janeiro) e Del Castilho. Ao serem estruturados por laços de vizinhança, normal que prevalecessem operários, funcionários públicos, caixeiros e outros trabalhadores de salários menores. Normal, também, que as mensalidades cobradas se tornassem, com o tempo, mais acessíveis, com a joia (ingresso), em geral, equivalente a uma mensalidade, posição muito diferente de clubes mais sofisticados como Botafogo, Flamengo e Fluminense. Da mesma forma, passava a não haver distinção de cor ou nacionalidade (com exceção dos clubes considerados "grandes" da capital). Mas o critério de vizinhança não era o único a propiciar a criação de clubes e associações esportivas: empregados de uma mesma loja ou operários de uma mesma fábrica passaram a estruturar suas agremiações futebolísticas.

Nos clubes ditos suburbanos do Rio de Janeiro, os estatutos das agremiações mostravam-se mais democráticos na admissão de novos sócios, sendo aceitos indivíduos, independentemente da cor, opção política e religiosa e nacionalidade ${ }^{12}$. Normalmente, seus dirigentes eram pessoas simples, que utilizavam endereço pessoal como indicativo da sede da agremiação criada (por vezes, até mesmo o endereço de atuação profissional; em outras, endereço desconhecido). Interessante observar que mesmo a estrutura do estatuto de uma pequena agremiação seguia o modelo das grandes. O uso do distintivo da organização do associado também lhe conferia certo "status". Foi o que ocorreu na Baixada Fluminense e em áreas da zona norte da cidade do Rio de Janeiro que, devido à procura por moradia por populares, impulsionou proprietários rurais a lotearem suas posses territoriais como forma de ganho rápido.

Devido ao fato de virar alternativa para a massa trabalhadora "expulsa" das regiões centrais do Rio de Janeiro, as regiões periféricas ganharam conotação pejorativa quando comparadas à região urbana remodelada. Tal conotação teria sido estimulada principalmente

\footnotetext{
${ }^{12}$ Para a obtenção de dados de formação e desenvolvimento de pequenos clubes foram analisados diversos periódicos, constituições estatutárias e registros de agremiações disponíveis no Arquivo Nacional do Rio de Janeiro.
} 
pela grande imprensa local, embora bairros da zona sul como Ipanema, Copacabana e Leblon poderiam ter a conotação de áreas de subúrbio (suburbanas), mas receberam outras descrições.

Uma vez que indivíduos que migraram para áreas de subúrbio levaram consigo costumes e hábitos florescentes adquiridos das regiões centralizadas e urbanizadas do início do século XX, não é de se estranhar a penetração do futebol como prática nas regiões periféricas, porém com um diferencial construído: identidade e identificação, próprio da discriminação a que estavam submetidos.

Nos estatutos da Associação Athlética Suburbana, por exemplo, não era exigida a indicação da profisssão dos atletas, abrindo a possibilidade estatutária para que os clubes contassem com jogadores que se dedicassem em tempo integral ao futebol.

No caso do futebol suburbano do Rio de Janeiro, vale destacar a cobertura à prática do jornal A Gazeta Suburbana, que circulou entre 1910 e 1920, cobrindo e impulsionando o futebol periférico através de coberturas que exaltaram o desempenho das equipes, incentivando, inclusive, a migração de muitos jogadores para os clubes do Rio de Janeiro mais bem estruturados (profissionalismo informal).

Paulatinamente, ao ver o futebol ganhar apreço entre populares, propagandas industriais e de ambientes de comércio passaram a ser veiculadas pela mídia (leia-se jornais) utilizando o esporte enquanto tema. A estratégia, claro, era a de atrair a atenção através de ações que agradavam os torcedores-consumidores. Muitas casas comerciais cariocas auxiliavam o football através da promoção de jogos, doação de taças e reserva de espaço em lojas e mercados para exposição de uniformes esportivos das equipes locais. Afinal, auxiliar o esporte permitia a determinada empresa construir uma boa imagem, passando a visão aos consumidores de que em seu interior havia a preocupação com a saúde física e emocional dos adeptos do esporte.

\section{O Futebol Suburbano Fluminense}

A ligação entre a produção de açúcar e Campos dos Goytacazes, norte fluminense, data do século XVII, quando da fundação do engenho de São Salvador (1650). No entanto, apenas cerca de um século após, a cultura do produto estruturou-se na região. A principal causa foi a decadência da produção açucareira no Nordeste brasileiro.

A estruturação de Usinas de Açúcar na região norte fluminense consolidou a formação de um grupo social emergente: a dos empresários do açúcar (usineiros) que, nas primeiras 
décadas do século XX, converteram Campos dos Goytacazes em um grande polo exportador do produto.

Em 1930, estavam estruturadas vinte e uma usinas na região, que, modernas, deram como destino aos antigos engenhos apenas a produção de aguardente e rapadura (PINTO, 1995, p.20). Segundo Pereira Pinto, “(...) cada usina era uma ilha dentro do município. Tinha suas regras, seus domínios, seus festejos do padroeiro e por consequência adquiria hábitos e tradições próprias. A usina era o centro do qual girava o trabalho" (PINTO, 1984, p.22).

Várias agremiações de futebol surgiram dentro de cada um destes mundos particulares em que se transformaram as Usinas da região norte fluminense, com destaque ao Goitacaz (de base mais popular) e ao Americano (mais elitizado). A criação do Instituto de Açúcar e Álcool (IAA), em 1933, em decorrência da Crise de 1929, durante o governo provisório de Getúlio Vargas, impulsionou ainda mais o setor industrial açucareiro na região. Tanto que, nas décadas seguintes, a produção local atingiu patamares gigantescos, principalmente devido aos efeitos da II Grande Guerra Mundial (1939-1945), com a Europa, em especial, ampliando a importação do produto.

Embora crescente, a produção açucareira de Campos dos Goytacazes trouxe a precarização das condições de trabalho, marcada, inclusive, pela exploração laboral infantil e feminina. Ou seja, a prosperidade das usinas ficou restrita aos proprietários e associados diretos a estes. A estruturação de várias equipes de futebol apoiadas pelas usinas e usineiros, teria minimizado o questionamento à exploração imposta aos colaboradores locais, caso do E C Cambaíba, de Heli Gomes.

O Esporte Clube Cambaíba, agremiação que emergiu a partir da fusão entre o Liberal Futebol Clube e Palmeiras Futebol Clube. Seus idealizadores foram funcionários da Usina Cambahyba, oficializado como clube de futebol em agosto de 1930. Entre seus vários presidentes (todos ligados ao comando da Usina), José Lisandro de Albernaz Gomes, um dos filhos de Heli Ribeiro Gomes, proprietário da Usina (que chegou a ocupar área de 6.763 hectares em 1979) (SANTANA, 1984, p. 264). A princípio, o objetivo inicial da agremiação foi o de produzir uma forma de lazer entre os trabalhadores locais. Com o sucesso do E C Cambaíba nos campeonatos campistas os objetivos ganharam outras proporções, tal como a promoção da família Heli Gomes.

Heli nasceu em Campos dos Goytacazes, filho de Hélio de Sousa Gomes (médico) e Sadi Ribeiro Gomes. Apesar de ligado às atividades econômicas do setor primário, Heli foi herdeiro político do sogro, Bartolomeu Lisandro. Com a projeção local de seu nome, foi eleito deputado federal pelo antigo Estado do Rio de Janeiro em 1958, sendo reeleito em 1962, 
filiando-se à antiga Arena (Aliança Renovadora Nacional, apoiadora do regime militar instalado no país a partir de 1964) em 1965. Em 1968, Heli tornou-se vice-governador indicado (biônico) do Rio de Janeiro na gestão de Jeremias Fontes (1967-1971). Em 1972, disputou a prefeitura de Campos, sendo derrotado nas urnas. A partir de então, Heli passou a dedicar-se à direção de sua usina de açúcar e álcool.

Outros clubes emergiram em torno da economia açucareira e tiveram o aparato de usineiros. Importante destacar que, já na primeira década do século XX, Campos dos Goytacazes possuía vinte e sete usinas de cana, álcool e aguardente. Para que se tenha uma ideia da importância econômica da região, em 1935 Campos chegou a ganhar a liderança da produção de açúcar do país respondendo por cerca de $90 \%$ da produção estadual e 14,3\% da produção nacional do produto.

As empresas açucareiras cederam benefícios como a estruturação de campos para a prática futebolística, agregando funcionários e habitantes locais (importante citar que o fato de uma agremiação possuir seu próprio campo se torna interessante por passar a possuir uma outra fonte de arrecadação através de alugueres às agremiações desprovidas do equipamento, além de notoriedade patrimonial). Segundo Pinto (PINTO, 1984, p.182), as usinas da primeira metade do século XX possuíam vida e estrutura própria, sendo os proprietários dos empreendimentos senhores absolutos dentro do raio proprietário. Aos seus empregados, em normalidade o "usineiro" fornecia escola básica, armazém para aquisição de gêneros alimentícios, moradia, atividades de lazer, promoção de eventos festivos, entre outros. Exigia, em contrapartida, lealdade e dedicação laboral.

Desta forma, surgiram mais agremiações como o União e Aliança (Usina de Queimado), Ypiranga (Morro do Coco), Atlético (Goytacazes), Santo Antônio (Beco), Martins Laje (Martins Laje), Rio Preto (Morangaba), Palmeiras e Liberal (Cambaíba), Tamandaré (Santa Maria), Santa Cruz (Santa Cruz), Nacional (Saturnino Braga), Comercial (Conselheiro Josino), Ururaí e União de Ururaí (Ururaí), Cruzeiro (Poço Gordo), Estrela (Ponta da Cruz), Santo Eduardo, Esporte Clube Italva e Cardoso Moreira Futebol Clube.

O apoio perdurou até a década de 1980, quando muitas das usinas entraram em processo de decadência. Com a crise, muitas das agremiações sucumbiram, demonstrando a dependência das mesmas em relação às usinas de açúcar e álcool. Em paralelo à crise açucareira, a descoberta de petróleo na região (Bacia de Campos), também colabora para a decadência das antigas elites locais.

Com a crise do setor sucroalcooleiro a partir da década de 1980, tanto a Usina Cambahyba quanto várias outras, passaram a enfrentar problemas para manutenção, 
acumulando dívidas junto à União. No caso da Cambahyba, em 1998 as fazendas do empreendimento (Complexo Agroindustrial de Cambahyba) foram consideradas improdutivas e passíveis de desapropriação para fins de Reforma Agrária.

Com a decadência açucareira e de seus derivados, várias agremiações do futebol campista sucumbiram. As que não foram desativadas, mantém-se com sérias dificuldades nos dias atuais. Outro clube de futebol que mostra uma história curiosa é o Volta Redonda Futebol Clube, estruturado de forma tardia, ou seja, apenas em 1976, a partir da fusão entre o Flamengo de Volta Redonda e o Guarani Esporte Clube, em pleno período de governos militares no país (1964-1985).

Volta Redonda, localizada no Vale do Paraíba fluminense, formou-se enquanto município a partir da Companhia Siderúrgica Nacional, fundada em 09 de Abril de 1941. Foi planejada enquanto cidade a partir do modelo de cidade industrial do arquiteto do socialista Tony Garnier. Segundo Lopes (LOPES, 1993), o plano de estruturação do município deveria exaltar o industrialismo e o nacionalismo proposto ao Brasil por Getúlio Vargas.

Porém, a atração de inúmeros migrantes em busca de colocação no mercado, impediu que o projeto de cidade modelo, com ocupação disciplinada de espaços, fosse seguido à risca. Para promover o lazer e obter certo controle sobre os trabalhadores da CSN (atualmente privatizada), o presidente da empresa, General Sylvio Raulino de Oliveira, passou a incentivar o futebol, a ponto de aproveitar-se da infraestrutura da Companhia para erguer o estádio de futebol local, inaugurado em 1950, no bairro Nossa Senhora das Graças, e que passou por reestruturação e foi reinaugurado em 2004, porém com a denominação de Estádio da Cidadania, simbolizando o fim da visão proletária da cidade e o advento da visão cidadã.

\section{Considerações finais}

A trajetória histórica de diversas agremiações de futebol permite afirmar que, da fundação de cada uma delas ao seu histórico de desenvolvimento, outros interesses brotaram, suplantando a ideia de controle sobre trabalhadores ou simplesmente de criação de momentos lazer entre os mesmos.

No futebol, há uma via de "duas mãos", a menos que seja praticado por puro lazer espontâneo: não apenas quem favorece se beneficia; o beneficiado, pelo patrocínio ou proteção obtida, pratica-o ou obtém condições para fazê-lo. Indivíduos e grupos apropriaramse de muitos clubes, beneficiando-os. Normalmente em busca de promoção pessoal, comercial e, principalmente, por interesses econômicos ou políticos. 
A título de exemplo, basta que observemos mais detalhadamente os caminhos traçados por algumas agremiações do Rio de Janeiro para que se comprove a afirmação. O futebol de fábrica surgiu como passatempo. Aos poucos, outros interesses brotaram, com empresários descobrindo na prática a possibilidade de se obter disciplina, controle sobre o tempo dos trabalhadores das fábricas, cerceamento sobre as atividades dos trabalhadores nos sindicatos, valorização de seus produtos e artigos, visualização positiva da empresa, além da imagem de que se preocupava com a condição física e de lazer de seus trabalhadores. A busca de patrocinadores para a prática - caso dos primeiros clubes operários que buscaram no patrão subsídios - também aponta para uma tendência do brasileiro: a de se sentir protegido e depender de quem considera superior.

É provável que, assim como nas escolas, os industriais tenham observado no futebol um esporte capaz de disciplinar seus operários, ocupando o tempo de lazer dos trabalhadores e impulsionando o gasto de energia com atividades desvinculadas indiretamente da produção fabril e o trabalho coletivo. Visto assim, o futebol estaria vinculado às ferramentas utilizadas para o que se denomina controle social.

O crescimento populacional dos principais centros urbanos do Brasil, caso de São Paulo e Rio de Janeiro, seguido de mobilizações reivindicatórias de novos componentes sociais como os operários, exigia a popularização de um esporte de massas. Perante à nova demanda, práticas corporais teriam sido estimuladas - caso do futebol, que ganhava admiradores no país (mesmo em pequenos municípios) -, fazendo com que autoridades governamentais e dirigentes industriais passassem a convencer-se de que a prática serviria ao propósito de ser estimada. Desta forma, municípios passaram a isentar de taxas os campos de futebol, patrões passaram a financiar pelejas entre seus trabalhadores e as forças policiais deixaram de reprimir rachas em terrenos vazios. Claro, não podemos deixar de levar em consideração o gosto das camadas populares junto ao esporte. Assim, a partir da apreciação e do gosto popular, cresceu o incentivo para que o jogo da bola fosse transformado em espetáculo de ação e contemplação.

A busca de patrocinadores para a prática - caso dos primeiros clubes operários que buscaram no patrão subsídios ou mesmo de agremiações que surgiram posteriormente aponta para uma tendência do brasileiro, que tem tendências a se sentir protegido e de depender de quem o favorece. O fantasma do coronelismo mantém-se no Brasil. Mesmo na atualidade, embora com menor peso. Através da prática, muitas agremiações prosperaram, numa espécie de "favoreça-me jogar e eu lhe favoreço em seus interesses". 


\section{Referências bibliográficas}

A GAZETA DE NOTÍCIAS, Rio de Janeiro, 20 abr. 1906.

AQUINO, Rubim Santos Leão. Futebol, uma paixão nacional. Rio de Janeiro: Jorge Zahar, 2002.

BOURDIEU, Pierre. Sobre a televisão. Rio de Janeiro: Jorge Zahar, 1997.

CARONE, Edgard. Introdução ao estudo do movimento operário no Brasil - 1877-1944: ensaios de opinião. São Paulo: [s. n.], 1979.

COELHO NETO, Paulo. O fluminense na intimidade. Rio de Janeiro: Fluminense Football Club, 1969.

ETCHEGARAY, Victor. O papel do Fluminense no advento dos esportes terrestres no Rio de Janeiro. Fluminense Football Club, Rio de Janeiro, n. 40, 17 jun. 1932.

HERSCHMANN, Micael; LERNER, Kátia. Lance de sorte: o futebol e o jogo do bicho na Belle Époque. Rio de Janeiro: Diadorim, 1992.

MALAIA, João Manuel. O futebol na cidade do Rio de Janeiro: microcosmo dos mecanismos de poder e exclusão no processo de urbanização das cidades brasileiras (1901-1933)". In: Encontro Regional de História: poder, violência e exclusão, 19, 2008, São Paulo. Anais [...]. São Paulo: ANPUH/SP - USP, 2008.

NEEDELL, Jeffrey D. Belle époque tropical. São Paulo: Cia Das Letras, 1993.

MARIVOET, Salomé. Inclusão social no e pelo desporto: um desafio do século XXI. In: PINTO, Paulo Mendes (coord.). Olímpico: os jogos num percurso de valores e de significados. Porto: Edições Afrontamento, 2013. p. 91-98.

PEREIRA, Leonardo Footballmania: uma história social do futebol no Rio de Janeiro, 19021938. Rio de Janeiro: Nova Fronteira, 2000.

As barricadas da saúde: vacina e protesto popular no Rio de Janeiro na Primeira

República. São Paulo: Editora Fundação Perseu Abramo, 2002.

PINTO, Antônio Carlos Pereira. Quem quebrou a casa de meu pai. Rio de Janeiro: Editora Comunità, 1984.

PINTO, Jorge Renato Pereira. O ciclo do açúcar em Campos. Campos: Ed. do Autor, 1995.

ROCHA, José da Silva. Clube de Regatas Vasco da Gama: histórico. Rio de Janeiro: Gráfica Olímpica Editora, 1975.

SANTANA, André Santos. O sucesso na região de Campos. 1984. Dissertação (Mestrado) Universidade Federal Rural do Rio de Janeiro, Rio de Janeiro, 1984.

SHIRTS, Matthew. Futebol no Brasil ou football in Brasil. In: SEBE, José; WITTER, José S. (org.). Futebol e cultura: coletânea de dados. São Paulo: Convênio IMESP/DAESP, 1982. 